ORIGINAL ARTICLE

\title{
Welding related occupational eye injuries: a narrative analysis
}

\author{
D A Lombardi, R Pannala, G S Sorock, H Wellman, T K Courtney, S Verma, G S Smith
}

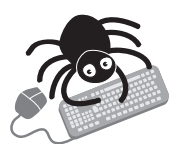

Table 5 and an appendix can be viewed on our website.

See end of article for authors' affiliations

......................

Correspondence to:

Dr D A Lombardi,

Quantitative Analysis Unit,

Liberty Mutual Research

Institute for Safety, 71

Frankland Road,

Hopkinton, MA 01748

USA; david.lombardi@

libertymutual.com

Accepted

10 December 2004
Objective: To determine the activities and circumstances proximal to a welding related occupational eye injury, a hybrid narrative coding approach derived from two well developed classification systems was developed to categorize and describe the activity, initiating process, mechanism of injury, object and/or substance, and the use of protective eyewear from the narrative text data reported for each injury.

Methods: Routinely collected workers' compensation claims over a one year period (2000) were analyzed from a large US insurance provider. An index term search algorithm of occupation, incident, and injury description fields identified 2209 potential welding related eye injury claims. After detailed review of these claims, 1353 welders and 822 non-welders were analyzed.

Results: During 2000, eye(s) as the primary injured body part accounted for $5 \%(n=26413)$ of all compensation claims. Eye injuries accounted for $25 \%$ of all claims for welders. Subjects were mainly male $(97.1 \%)$ and from manufacturing (70.4\%), service (11.8\%), or construction (8.4\%) related industries. Most injuries were foreign body $(71.7 \%)$ or burn $(22.2 \%)$ and $17.6 \%$ were bilateral. Common activities include welding (31.9\%) and/or grinding (22.5\%). Being struck by an airborne object occurred in $56.3 \%$ of cases. Non-welders showed similar patterns except that burns $(43.8 \%)$ were more frequent and more often initiated by another worker (13.9\%).

Conclusions: Narrative injury text provides valuable data to supplement traditional epidemiologic analyses. Workers performing welding tasks or working nearby welders should be trained to recognize potential hazards and the effective use of proper safety equipment to prevent ocular injury.
$E$ ye injuries account for a substantial proportion of all work related injuries, ${ }^{1-3}$ including $12 \%$ of all workers compensation claims among carpenters ${ }^{2}$ and $11 \%$ of all injuries to construction workers requiring an emergency room visit. ${ }^{3}$ Welders are at particularly high risk for eye injuries. A Canadian study reported that welders represented $21 \%$ of all eye injury claims. ${ }^{4}$ According to the US Bureau of Labor Statistics (BLS), welders, cutters, and welding machine operators held about 521000 jobs in 2000.5 The welding process exposes workers to a number of sources of mechanical, radiant, thermal, or chemical energy. ${ }^{6}$ A two year study of eye injury among workers in automobile manufacturing reported that $15 \%$ of the most common types of injuries (foreign body, corneal abrasion, and chemical injury) were welding related. ${ }^{7}$ Welding is also the second leading cause of consumer product related ocular trauma. ${ }^{8}$

Welding can also be performed by workers other than welders-for example, pipe fitters or construction workers. A recent study of work related eye injuries reported that workers who are "sometimes" or "often" exposed to welding had a fourfold increased risk of an eye injury compared with non-exposed workers." However, little is known regarding the specific activities or circumstances involved in eye injuries among welders.

Narrative text analysis has become a useful adjunct to traditional epidemiologic analyses in identifying workplace hazards and possible injury prevention strategies. ${ }^{10-13}$ This method allows for the analysis of qualitative data, routinely collected in administrative data systems, that are typically not coded for detailed analyses of injury circumstances. For example, this method was used to identify pre-crash manoeuvres and crash types from insurance claims narratives of vehicle crashes in roadway construction zones, ${ }^{10}$ in comparing international causes of fatal work related injuries, ${ }^{11}$ and in improving the information quality collected by emergency department surveillance systems. ${ }^{12}$

To identify and describe the circumstances and events leading to eye injury among welders, we investigated all welding related eye injuries reported to a large US based workers' compensation provider during 2000. Routinely collected narrative data describing the injury and related events were assessed using an original narrative coding approach to categorize the activity, initiating process, mechanism, object, or substance causing the injury and the use of protective eyewear.

\section{METHODS}

\section{Design and data sources}

Workers' compensation claims from period l January through 31 December 2000 were extracted from all claims filed with a US based workers' compensation insurance provider $(n=531214)$. These claims represented medical only, lost work time (indemnity), or zero cost claims (those with no medical or indemnity costs). Five percent of all claims $(\mathrm{n}=26413)$ had eye(s) as the primary injured body part(s).

Welders were identified using a substring text search for the term "weld" in the occupation field $(n=1368)$. Nonwelders (those not selected based upon occupational title) sustaining a welding related eye injury $(n=841)$ were identified using a narrative substring text search using for the terms "weld", "braz", or "solder" (to identify welding, brazing, or soldering) in the injury and incident ("accident")

Abbreviations: PPE, personal protective equipment. 
description fields (for example, pipe fitters with an eye injury while welding).

Injuries involving multiple body parts, including the eye, were excluded from the study as the etiology of these injuries (for example, motor vehicle crashes) are likely different from welding related eye injuries. An index term search for "eye" as a secondary body part injured was performed using the injury and accident description fields (including multiple injuries, head injury, injury to facial bones or facial soft tissue, multiple systems, artificial appliance, and unknown). This yielded approximately 1500 eye injury claims (about 5\% more) from the 531214 claims. If the relative proportion of claims attributed to welding were the same as for single eye injuries, this would yield 75 additional welding related claims.

The combined selection criteria yielded 2209 potential welding related eye injury claims. These claims were then manually reviewed for accuracy and completeness. Thirty four $(1.5 \%$ of the total) claims were excluded; 14 were duplicates and 20 had either miscoded body part(s) or were incomplete. The final sample for analysis included 2175 workers with welding related eye injury claims, accounting for $8.2 \%$ of all eye injuries in 2000 .

The Liberty Mutual Research Institute for Safety's Institutional Review Committee for the Protection of Human Subjects approved the study.

\section{Narrative coding}

Our narrative coding approach (see http://www.injuryprevention.com/supplemental for Appendix 1) is adapted from an approach originally proposed by Lincoln et al for coding safety report narratives. ${ }^{13}$ This hybrid approach was derived from two well developed classification systems, the Occupational Injury and Illness Classification Manual, ${ }^{14}$ developed by the Bureau of Labor Statistics and the International Classification of External Causes of Injury from the World Health Organization. ${ }^{15}$ Our approach permitted the analysis of two routinely collected narrative text fields: "accident description" which describes the activity at the time of the incident and injury description which contains the nature of the injury. Each field was up to 120 characters of text. Our objective was to develop a customized coding approach that would provide a clear understanding of the circumstances proximal to a welding related eye injury.

Coding categories included activity (the activity or task that the worker was performing when the injury occurred), initiating agent (the initiating process resulting in a specific mechanism of injury), intent (for example, intentional or unintentional), mechanism of injury (the operation or action that caused the object or substance to contact the eye), source (object or substance impacting the eye), any mention of the use or non-use of personal protective equipment (PPE) (yes/ no), and eye involved (right, left, or both). Intent was initially coded; however as $99 \%$ of claims were unintentional, this data field was dropped. A trained reviewer (RP), who codeveloped the coding approach, initially coded all 2175 claims. Ambiguous descriptions of incidents $(n=43)$ were reviewed and coded by consensus agreement among four researchers.

A typical incident description for narrative coding might be, "the employee grinding a weld when piece of metal flew under safety glass into right eye" with the injury description "metal sliver in right eye". The resulting codes would be "grinding" as the activity, "normal mechanical work process initiated" (not involving a malfunction) as the initiating agent, "propelled or airborne" as the mechanism of injury, "particulate or small solid" as the object or substance causing the injury, "yes" for PPE use, and "right" for eye involved.

\section{Industry coding}

Workers' compensation claims were precoded using the four digit 1987 OSHA Standard Industrial Classification (SIC) system to identify the primary business of the establishment.

\section{Data analysis}

Descriptive statistics (that is, frequencies, column percentages, means, and SEM) were calculated for demographic, occupational, and injury related variables (for example, sex, age, nature of injury) for welders and non-welders separately. Narrative analysis variables were cross-classified (for example, injury source by mechanism) and frequencies and column percentages were calculated. As different criteria were used to select welders and non-welders, statistical comparisons of these two groups were not conducted and descriptive comparisons cannot be made. All data analyses were conducted using SAS (Version 8, SAS Institute Inc, Cary, NC, USA).

The underlying population at risk of reporting an eye injury claim was unknown in this study (denominators), precluding the calculation and comparison of incidence rates. Proportionate injury ratios were estimated to compare nature of injury between welders and all other workers reporting eye injuries during the same year (2000). Proportionate injury ratios and associated 95\% confidence intervals were calculated using methods for calculating proportionate mortality ratios. ${ }^{16}$ The PIR is interpreted as whether the observed proportion of cases in each stratum is greater or less than what would have been expected based on the distribution of a selected reference population (for example, non-welders). As proportions must equal $100 \%$, an increase in one nature of injury category will be offset by a decrease in another.

\section{RESULTS}

\section{Worker characteristics}

Eye injuries accounted for $5.0 \%(n=26413)$ of all workers' compensation claims. Welders comprised 1353 cases or $5.1 \%$ of all eye injury claims. Eye injuries accounted for $25 \%$ of all claims filed by welders; $97 \%$ were male, mean (standard error of the mean) age 34.9 (SEM 0.3) years (table 1). Primary SIC category was available for $64.4 \%$ of workers; manufacturing $(70.4 \%)$, services $(11.8 \%)$, and construction $(8.4 \%)$. The most frequent two digit subgroups under manufacturing were industrial, commercial machinery, computer equipment, and fabricated metal products.

The second narrative index search criteria identified 822 non-welders with an eye injury from a welding related task (3.1\% of all eye injury claims). These workers were similar to welders with respect to sex and age, mostly employed in manufacturing $(47.3 \%)$, construction $(21.2 \%)$, and services $(12.5 \%)$. The most common non-welder occupations were mechanics, laborers, maintenance workers, assemblers, pipe fitters, boilermakers, ironworkers, millrights, and riggers.

\section{Injury characteristics}

Of the combined 2175 welding related eye injury claims, $24.2 \%$ were bilateral; $17.6 \%$ of welders and $35.1 \%$ of non-welders had bilateral injuries. Single eye injuries were distributed evenly among the left and right eye (table 2). The most frequent nature of injury was foreign body $(63.4 \%)$ and then burns $(30.3 \%)$. Among welders, foreign bodies (71.7\%) and burns (22.2\%) were most common, followed by inflammation, laceration, and contusions (each comprised less than 3\% of the total). In comparing the nature of injury for welders $(n=1353)$ to all other worker eye injury claims reported for the year $(n=25060)$ (see fig 1 ), welders had proportionally more burns than workers in other occupations reporting eye injuries ( $\mathrm{PIR}=4.7 ; 95 \% \mathrm{CI} 4.2$ to 5.2 ) demonstrating greater exposure 


\begin{tabular}{|c|c|c|c|c|c|c|}
\hline \multirow[b]{2}{*}{ Characteristic } & \multicolumn{2}{|c|}{ Welders $(n=1353)$} & \multicolumn{2}{|c|}{$\begin{array}{l}\text { Non-welders } \\
(\mathrm{n}=822)\end{array}$} & \multicolumn{2}{|c|}{ Total $(n=2175)$} \\
\hline & $\mathbf{n}$ & (\%) & $\mathbf{n}$ & $(\%)$ & $\mathbf{n}$ & (\%) \\
\hline \multicolumn{7}{|l|}{ Sex } \\
\hline Male & 1314 & (97.1) & 798 & (97.1) & 2112 & (97.1) \\
\hline Female & 39 & $(2.9)$ & 24 & $(2.9)$ & 63 & $(2.9)$ \\
\hline \multicolumn{7}{|l|}{ Age $^{*}$ (years) } \\
\hline $15-20$ & 30 & $(2.2)$ & 32 & $(4.0)$ & 62 & (2.9) \\
\hline $20-24$ & 199 & (14.9) & 103 & (12.8) & 302 & (14.1) \\
\hline $25-34$ & 480 & (35.9) & 236 & (29.3) & 716 & (33.4) \\
\hline $35-44$ & 371 & (27.8) & 261 & (32.4) & 632 & $(29.5)$ \\
\hline $45-54$ & 201 & (15.0) & 129 & (16.0) & 330 & (15.4) \\
\hline $55-64$ & 54 & $(4.0)$ & 40 & $(5.0)$ & 94 & $(4.4)$ \\
\hline $65+$ & 3 & $(0.2)$ & 4 & (0.5) & 7 & (0.3) \\
\hline Mean (SEM) & 39 & $(0.28)$ & 36.0 & (0.38) & 35.3 & (0.23) \\
\hline \multicolumn{7}{|l|}{ SIC categoryt } \\
\hline Manufacturing & 573 & (70.4) & 277 & (47.3) & 850 & $(60.7)$ \\
\hline Construction & 68 & $(8.4)$ & 124 & (21.2) & 192 & (13.7) \\
\hline Services & 96 & (11.8) & 73 & (12.5) & 169 & (12.1) \\
\hline Wholesale and retail trade & 40 & $(4.9)$ & 43 & $(7.3)$ & 83 & (5.9) \\
\hline $\begin{array}{l}\text { Transportation, communications, electric, } \\
\text { gas, sanitation services }\end{array}$ & 19 & (2.3) & 40 & (6.8) & 59 & (4.2) \\
\hline $\begin{array}{l}\text { Finance, insurance, real estate, public } \\
\text { administration }\end{array}$ & 13 & (1.6) & 14 & (2.4) & 27 & (1.9) \\
\hline Agriculture, forestry, fishing, mining & 5 & (0.6) & 7 & (1.2) & 12 & (0.9) \\
\hline Non-classifiable estimate & 0 & $(0.0)$ & 8 & (1.4) & 8 & (0.6) \\
\hline
\end{tabular}

to UV radiation (note: $87.3 \%$ of burns to welders was UV ray induced) and proportionally fewer lacerations, contusions, inflammation, and other natures of injury. The proportion of foreign bodies was generally similar.

\section{Narrative analysis \\ Welders}

Welding (31.9\%) and grinding $(22.5 \%)$ were the most common activities at the time of injury (table 3). Activities also included cleaning or brushing (3.7\%), or observing or being a bystander (3.0\%) among others. Almost 22\% of activities were non-classifiable due to a lack of information. Injury sources (table 4 ) were frequently particulates or small solids $(63.4 \%)$ and ultraviolet rays $(19.7 \%)$. The primary mechanism of particulates, hot substances, and solid objects was propelled or airborne (ranging from 50-77.6\%), whereas chemicals, liquids, and caustics were primarily from splashes or sprays (77.3\%). Injuries (table 5; see http:// www.injuryprevention.com/supplemental) were most often

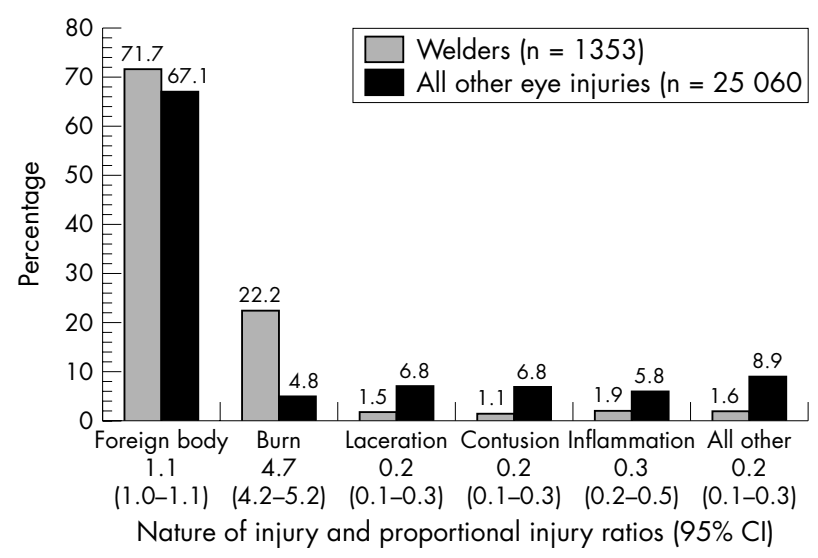

Figure 1 Comparison of nature of injury and proportional injury ratios for welders with other workers with work related eye injury claims in 2000. initiated by the work process $(74.9 \%)$ during a normal mechanical operation (that is, not a malfunction) $(86.8 \%)$. Processes initiated by another worker (or co-worker) accounted for $4.7 \%$ of all eye injuries and most often during a normal mechanical process $(93.6 \%$ ). The use of PPE (for example, safety goggles, masks, helmets) was mentioned only in $14.7 \%$ of all welders' claims (data not presented), of which 20.6\% reported donning or removing their PPE and $7.0 \%$ reported not wearing PPE at all.

\section{Non-welders}

Among non-welders, welding (49.4\%), grinding (9.3\%), and multiple tasks $(6.1 \%)$ were the most frequent activities at the time of their injury (table 3 ). Observing, standing, walking, or assisting a welder accounted for another $6.1 \%$ of injuries. Injury sources (table 4) commonly were ultraviolet rays (41.1\%), particulates or small solids $(40.4 \%)$, and hot substances $(5.7 \%)$. As in welders, the mechanism of particulates, hot substances, and solid objects was primarily propelled or airborne (ranging from 58.8-77.1\%). Chemicals, liquids, and caustics were most often due to splashes or sprays (80.0\%). The injury process (see http://www. injuryprevention.com/supplemental for table 5) was typically initiated by the work process $(74.6 \%)$ not involving a mechanical malfunction (91.4\%). Processes initiated by another worker accounted for $13.9 \%$ of all eye injuries and most often during a normal mechanical process (96.5\%). Personal protective equipment (PPE) use or non-use was mentioned in $17.8 \%$ of all non-welders' claims (data not shown). Of these 146 cases, $24.0 \%$ reported donning or removing their PPE and $11.6 \%$ reported not wearing any PPE at the time of their injury.

\section{DISCUSSION}

Traumatic eye injury continues to be an important occupational health and safety issue for workers who are engaged in the welding processes. In our study, welders comprised 5.1\% and workers engaged in welding related activities comprised $8.2 \%$ of all reported eye injuries. The proportion of eye injuries to welders is similar to most other studies: $9.1 \%$ of 
Table 2 Eye injury characteristics for welders and non-welders

\begin{tabular}{|c|c|c|c|c|c|c|}
\hline \multirow[b]{2}{*}{ Characteristic } & \multicolumn{2}{|c|}{ Welders $(n=1353$ ) } & \multicolumn{2}{|c|}{ Non-welders ( $n=822$ ) } & \multicolumn{2}{|c|}{ Total $(n=2175)$} \\
\hline & $\mathrm{n}$ & (\%) & $\mathrm{n}$ & $(\%)$ & $n$ & $(\%)$ \\
\hline \multicolumn{7}{|l|}{ Injured eye* } \\
\hline Single & 1113 & (82.4) & 528 & (64.9) & 1641 & (75.8) \\
\hline Right & 443 & $(39.8)$ & 203 & (38.4) & 646 & (39.4) \\
\hline Left & 433 & (38.9) & 169 & $(32.0)$ & 602 & (36.7) \\
\hline Unspecified & 237 & (21.3) & 156 & $(29.5)$ & 393 & (24.0) \\
\hline Bilateral & 238 & (17.6) & 285 & (35.1) & 523 & (24.2) \\
\hline \multicolumn{7}{|l|}{ Nature of injury } \\
\hline Foreign body & 970 & (71.7) & 409 & $(49.8)$ & 1379 & (63.4) \\
\hline Burn & 300 & (22.2) & 360 & (43.8) & 660 & (30.3) \\
\hline Inflammation & 26 & (1.9) & 21 & (2.6) & 47 & (2.2) \\
\hline Laceration & 20 & (1.5) & 5 & $(0.6)$ & 25 & (1.2) \\
\hline Contusion & 15 & (1.1) & 8 & (1.0) & 23 & (1.1) \\
\hline All othert & 22 & (1.6) & 19 & (2.3) & 41 & (1.9) \\
\hline
\end{tabular}

worker compensation eye injury claims in West Virginia ${ }^{1}$ and $6.0 \%$ of more serious eye injuries resulting in days away from work, ${ }^{17}$ but is in marked contrast to another study, ${ }^{4}$ where welders comprised $21 \%$ of all worker compensation eye injury claims. Possible reasons for this discrepancy are unknown; however, the latter study was conducted 20 years ago and circumstances such as welding practices or industry make-up may have changed. For example, the rate of non-fatal eye injuries and illness with days away from work decreased $47 \%$ during the period 1993-2000 (11.2 per 10000 full time workers to 5.9 per 10000$).{ }^{18}$ Welders also may have experienced similar decreases in overall injury rates as other workers. However, in our database, eye injury claims continued to account for a significant proportion (25\%) of all workers' compensation claims filed by welders in 2000 .

An important contribution of our study is the availability of data that describe the nature and circumstances of a large case series of welding related injuries. We found no comparable studies that provide similar data on workers doing welding related activities, including Reesal's study which analyzed only 395 welders. ${ }^{4}$ One important finding is that non-welders doing welding related activities experienced a high proportion of burns from ultraviolet rays in spite of the well known hazards of UV light (see tables 2 and 4). These differences may be in part due to the selection criteria used to abstract claims; however, it is clear that training in the proper use of personal protective equipment (for example, protective eyewear) is critical for all workers performing welding related tasks.

In our study, foreign body injuries accounted for $71.7 \%$ and burns accounted for $22.2 \%$ of all injuries. Reesal et al reported similar findings $(72 \% \text { and } 25 \% \text {, respectively })^{4}$ and similar data on the location and pattern of eye injuries.

The injuries in our study were mostly minor; only $1.2 \%$ of those injured were disabled long enough to qualify for wage replacement (indemnity) benefits. The average cost of a welding related eye injury was only slightly higher than the cost (\$157) for medical only eye injury claims among construction workers. ${ }^{2}$

Injuries resulting from processes initiated by another worker (or co-worker) accounted for $8.1 \%$ of our eye injuries (4.7\% for welders and $13.9 \%$ for non-welders); 177 injuries

\begin{tabular}{|c|c|c|c|c|c|c|}
\hline & \multicolumn{2}{|c|}{ Welders ( $n=1353$ ) } & \multicolumn{2}{|c|}{$\begin{array}{l}\text { Non-welders } \\
(\mathrm{n}=822)\end{array}$} & \multicolumn{2}{|c|}{ Total $(n=2175)$} \\
\hline & $\mathbf{n}$ & $(\%)$ & $\mathrm{n}$ & $(\%)$ & $\mathrm{n}$ & (\%) \\
\hline \multicolumn{7}{|l|}{ Welding related activity } \\
\hline Welding & 432 & (31.9) & 406 & (49.4) & 838 & (38.5) \\
\hline Grinding & 304 & (22.5) & 76 & $(9.3)$ & 380 & (17.5) \\
\hline Multiple tasks & 32 & (2.4) & 50 & (6.1) & 82 & (3.8) \\
\hline Standing/walking/observing & 40 & (3.0) & 33 & (4.0) & 73 & (3.4) \\
\hline Cleaning/brushing & 50 & (3.7) & 22 & $(2.7)$ & 72 & (3.3) \\
\hline Manual material handling & 37 & (2.7) & 19 & (2.3) & 56 & (2.6) \\
\hline Chipping & 35 & (2.6) & 15 & (1.8) & 50 & (2.3) \\
\hline Other $^{*}$ & 27 & (2.0) & 12 & (1.5) & 39 & (1.8) \\
\hline Cutting & 34 & (2.5) & 3 & (0.4) & 37 & (1.7) \\
\hline Work with machinery/drilling & 26 & (1.9) & 7 & (0.9) & 33 & (1.5) \\
\hline Sanding/sand blasting & 21 & (1.6) & 9 & (1.1) & 30 & (1.4) \\
\hline Soldering/brazing & 1 & (0.1) & 25 & (3.0) & 26 & (1.2) \\
\hline Assisting welder & 6 & (0.4) & 18 & (2.2) & 24 & (1.1) \\
\hline Putting on/removing PPE & 14 & (1.0) & 7 & (0.9) & 21 & (1.0) \\
\hline Non-classifiable or missing & 294 & $(21.7)$ & 120 & (14.6) & 414 & (19.0) \\
\hline Total & 1353 & $(100.0)$ & 822 & $(100.0)$ & 2175 & (100.0) \\
\hline
\end{tabular}




\begin{tabular}{|c|c|c|c|c|c|c|}
\hline & \multicolumn{2}{|c|}{ Welders ( $n=1353$ ) } & \multicolumn{2}{|c|}{ Non-welders ( $n=822$ ) } & \multicolumn{2}{|c|}{ Total $(n=2175)$} \\
\hline & $\mathbf{n}$ & (\%) & $\mathbf{n}$ & (\%) & $\mathbf{n}$ & (\%) \\
\hline \multicolumn{7}{|l|}{ Source/mechanism } \\
\hline Particulate/small solid & 858 & (63.4) & 332 & (40.4) & 1190 & (54.7) \\
\hline Propelled/airborne & 666 & (77.6) & 256 & (77.1) & 922 & (77.5) \\
\hline Falling object & 38 & $(4.4)$ & 26 & $(7.8)$ & 64 & (5.4) \\
\hline Other* & 18 & (2.1) & 3 & (0.9) & 21 & (1.8) \\
\hline Smoke/irritation & 5 & (0.6) & 5 & (1.5) & 10 & (0.8) \\
\hline Splash/spray & 0 & $(0.0)$ & 2 & $(0.6)$ & 2 & $(0.2)$ \\
\hline Non-classifiable or missing & 131 & (15.3) & 40 & (12.1) & 171 & (14.4) \\
\hline Ultraviolet rays $\dagger$ & 266 & (19.7) & 338 & (41.1) & 604 & (27.8) \\
\hline Hot substance & 41 & (3.0) & 47 & (5.7) & 88 & $(4.0)$ \\
\hline Propelled/airborne & 35 & (85.4) & 33 & (70.2) & 68 & (77.3) \\
\hline Other* & 2 & $(4.9)$ & 6 & (12.9) & 8 & (9.1) \\
\hline Splash/spray & 1 & (2.4) & 5 & (10.6) & 6 & (6.8) \\
\hline Falling object & 1 & (2.4) & 3 & $(6.4)$ & 4 & (4.6) \\
\hline Smoke/irritation & 1 & (2.4) & 0 & $(0.0)$ & 1 & (1.1) \\
\hline Non-classifiable or missing & 1 & (2.4) & 0 & $(0.0)$ & 1 & (1.1) \\
\hline Solid object & 28 & $(2.1)$ & 17 & $(2.1)$ & 45 & (2.1) \\
\hline Propelled/airborne & 14 & (50.0) & 10 & (58.8) & 24 & (53.3) \\
\hline Other* & 9 & (32.2) & 3 & (17.6) & 12 & (26.7) \\
\hline Falling object & 3 & (10.7) & 3 & (17.7) & 6 & (13.3) \\
\hline Non-classifiable or missing & 2 & (7.1) & 1 & $(5.9)$ & 3 & $(6.7)$ \\
\hline Chemicals, liquid, or caustics & 22 & (1.6) & 5 & $(0.6)$ & 27 & (1.2) \\
\hline Splash/spray & 17 & (77.3) & 4 & (80.0) & 21 & $(77.8)$ \\
\hline Other* & 2 & (9.1) & 0 & $(0.0)$ & 2 & $(7.4)$ \\
\hline Propelled/airborne & 0 & $(0.0)$ & 1 & (20.0) & 1 & (3.7) \\
\hline Non-classifiable or missing & 3 & (13.6) & 0 & $(0.0)$ & 3 & (11.1) \\
\hline Other sources $\ddagger$ & 2 & $(0.2)$ & 7 & (0.9) & 9 & (0.4) \\
\hline Non-classifiable or missing & 136 & (10.1) & 76 & (9.3) & 212 & (9.8) \\
\hline Propelled/airborne & 45 & (33.1) & 19 & $(25.0)$ & 64 & (30.2) \\
\hline Smoke/irritation & 17 & (12.5) & 16 & $(21.1)$ & 33 & (15.6) \\
\hline Other* & 6 & $(4.4)$ & 3 & $(4.0)$ & 9 & (4.3) \\
\hline Falling object & 2 & (1.5) & 1 & (1.3) & 3 & (1.4) \\
\hline Splash/spray & 1 & $(0.7)$ & 0 & $(0.0)$ & 1 & $(0.5)$ \\
\hline Non-classifiable or missing & 65 & $(47.8)$ & 37 & $(48.7)$ & 102 & $(48.1)$ \\
\hline Total & 1353 & $(100.0)$ & 822 & 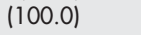 & 2175 & (100.0) \\
\hline $\begin{array}{l}\text { *Other mechanisms include sto } \\
\text { †All mechanisms were ultravio } \\
\text { tOther sources include multipl } \\
\text { airborne, ultraviolet radiation, }\end{array}$ & stances $\mathrm{h} /$ spro & ng objec & $\begin{array}{l}\text { at/pre } \\
\text { ectricit }\end{array}$ & $\begin{array}{l}\text {, other con } \\
d \text { the meche }\end{array}$ & $\begin{array}{l}\text { ct, or } n \\
\text { isms in }\end{array}$ & $\begin{array}{l}\text { ole. } \\
\text { ed propell }\end{array}$ \\
\hline
\end{tabular}

(68.4\%) were from UV rays $(49.1 \%$ for welders and $79.0 \%$ for non-welders), and $22.6 \%$ were from particulates or small solids. Non-welders, such as pipe-fitters, laborers, and helpers were often walking past or around a welder leading to flash burns to the eye. The use or non-use of personal protective equipment (PPE) (for example, safety goggles, masks, helmets) was only mentioned in $14.7 \%$ of welders' and $17.8 \%$ of non-welders' claims, suggesting a very important area for intervention. Welding activity has considerable potential to affect other workers and the perimeter around this work should be considered hazardous. For example, that area could be 100 square feet ( 10 by 10 ) or greater; however this distance could be influenced by the confined nature of some welding work. It is apparent that workers near welding activity would benefit from training in the proper use of PPE, as most work related ocular injuries are potentially preventable. ${ }^{19}$

There are several limitations related in this study. Workers' compensation claims may underestimate the occurrence of injuries, including eye injuries. Additionally, the majority of eye injuries in our study were minor in severity and these data may not be representative of welding related eye injuries of greater severity treated in hospital emergency rooms. The narrative analysis method is also limited by the completeness and consistency of the available text data. ${ }^{13}$ Additionally, sensitivity is likely to be better than specificity-that is, when keywords are found in the narrative they probably indicate real contributions to the incident/injury. It is unknown whether there are words that were truncated, forgotten, lost in conversation, or abbreviated by those reporting or recording the claim. Thus, narrative analysis likely underestimates the magnitude of these contributing factors/ circumstances to eye injuries.

Another limitation of this study is in the method of injury type classification. The current study used the broad nature of injury categories rather than ICD-9 or other similar diagnostic codes to classify injuries. For example, in our coding system, keratitis ("welder's flash") and burns from hot slag are confounded and would be coded as burn. However, compared with the findings reported by Islam et al which used ICD-9 coding, ${ }^{1}$ both data sources rank foreign body (ICD-9; 930-930.9) as the leading type of compensable injury and a similar proportion of burns (ICD-9; 940-940.9) are reported (approximately 5\%).

Strengths of this study include the relatively large number of cases for analysis, including 1353 welders and 822 nonwelders (a much larger sample size than other published studies), and a diverse study population from multiple industries. These results should be fairly representative of the insured working population.

Eye injuries are considered to be largely preventable especially if adequate eye protection is used and appropriate machine guards are positioned over obvious hazards. ${ }^{19} 20 \mathrm{~A}$ detailed review of prevention strategies is beyond the scope of this paper; however, common and effective approaches to the prevention of injury from the welding process have been 


\section{Key points}

- Injuries to the eye as the primary body part accounted for $5 \%$ of all workers' compensation claims for a large US insurance provider.

- The most common welding related eye injuries are foreign body or burns. Frequent work activities at the time of injury include welding, grinding, cleaning, brushing, or observing a welder.

- Injury narratives provided valuable data for describing the circumstances of welding related and other injuries.

- Workers performing welding tasks or working near welders should be trained to recognize potential hazards and the effective use of proper safety equipment to prevent ocular injury.

published..$^{21}$ They suggest a well communicated eye safety policy for employees, protective eyewear available at no cost to workers (meeting ANSI Z87.1-1989), periodic vision screening, and spot checks for the use of PPE when hazards are present. As many welding related eye injuries are due to foreign bodies, we emphasize focusing on the prevention of hazards associated with propelled particulates during welding and grinding activities through engineering controls and improved tool design.

Developing preventive strategies for reducing welding related eye injuries requires a detailed understanding of injury circumstances such as is provided in our study. For example, the fact that UV light exposure burns continue to occur to welders suggests a need to better implement known strategies such as UV light shields. More studies are needed to determine the important barriers to the use of known prevention strategies (for example, PPE use) and to identify potentially modifiable worker related, work environment, and work equipment related transient risk factors for eye injuries. These studies will reduce the burden of eye injuries and the potential risk of long term serious sequelae.

\section{ACKNOWLEDGEMENTS}

The authors are grateful to Dr Hester Lipscomb, Dr Mary F Lesch, Dr William Shaw, and Ms Leitha Bundrick for their thoughtful comments on this manuscript.

\section{Authors' affiliations}

D A Lombardi, H Wellman, T K Courtney, S Verma, G S Smith, Liberty Mutual Research Institute for Safety, Hopkinton, MA, USA
D A Lombardi, R Pannala, Department of Biostatistics and Epidemiology, University of Massachusetts-Amherst, School of Public Health and Health Sciences, Amherst, MA, USA

G S Sorock, Center for Injury Research and Policy, Johns Hopkins

Bloomberg School of Hygiene and Public Health, Baltimore, MD, USA

\section{REFERENCES}

1 Islam SS, Doyle EJ, Velilla A, et al. Epidemiology of compensable work-related ocular injuries and illnesses: Incidence and risk factors. J Occup Environ Med 2000:42:575-81.

2 Lipscomb HJ, Dement JM, McDougall V, et al. Work-related eye injuries among union carpenters. Appl Occup Environ Hyg 1999; 14:665-76.

3 Welch LS, Hunting KL, Mawudeku A. Injury surveillance in construction: Eye injuries. Appl Occup Environ Hyg 2001;16:775-62.

4 Reesal MR, Dufresne RM, Suggett D, et al. Welder eye injuries. J Occup Med 1989;31:1003-6.

5 US Department of Labor, Bureau of Labor Statistics. Occupational outlook handbook, 2002-03 edition, Bulletin 2540. Washington, DC: Superintendent of Documents, US Government Printing Office, 2002, Available at http:// www.bls.gov/oco/ (accessed 16 June 2003).

6 Pabley AS, Keeney AH. Welding processes and ocular hazards and protection. Am J Ophthalmol 1981;92:77-84.

7 Wong TY, Lincoln A, Tielsch JM, et al. The epidemiology of ocular injury in a major US automobile corporation. Eye 1998;12:870-4.

8 Sasty SM, Copeland RA, Mezghebe HM, et al. Consumer product-related ocular trauma. J Natl Med Assoc 1995;87:349-52.

9 Yu TS, Liu H, Hui K. A case-control study of eye injuries in the workplace in Hong Kong. Ophthalmology 2004:111:70-4.

10 Sorock G, Ranney T, Lehto MR. Motor vehicle crashes in roadway construction workzones: An analysis using narrative text from insurance claims. Accid Anal Prev 1996;28:131-8.

11 Williamson A, Feyer A-M, Stout N, et al. Use of narrative analysis for comparisons of the causes of fatal accidents in three countries: New Zealand, Australia, and the United States. Inj Prev 2001 ; (Suppl 1):i15-20

12 Jones SJ, Lyons RA. Routine narrative analysis as a screening tool to improve data quality. Inj Prev 2003;9:184-6.

13 Lincoln AE, Sorock GS, Courtney TK, et al. Using narrative text and coded data to develop hazard scenarios for occupational injury interventions. Inj Prev 2004;10:249-54.

14 US Department of Labor, Bureau of Labor Statistics. Occupational injury and illness classification manual. Washington, DC: Superintendent of Documents, US Government Printing Office, 2002, Available at http://www.bls.gov/iif/ oshsecl.htm (accessed 19 January 2005).

15 WHO Working Group on Injury Surveillance Methods. International classification of external causes of injuries (ICECI): Data Dictionary, version 1.1a. Adelaide: Consumer Safety Institute, Amsterdam and AlHW National Injury Surveillance Unit, 2003.

16 Checkoway H, Pearce N, Kreibel D. Research methods in occupational epidemiology, 2nd edn. New York: Oxford University Press 2004:70-2.

17 Harris PM. Nonfatal Occupational Injuries Involving the Eyes, 2002. Compensation and working conditions online, 6-30-2004. US Department of Labor, Bureau of Labor Statistics. Available at http://www.bls.gov/opub/cwc (accessed 27 July 2004)

18 Bureau of Labor Statistics, US Department of Labor. Washington DC, 2002. Available at http://stats.bls.gov/iif/home.htm (reference run date 07/20/03).

19 Lipscomb HJ. Effectiveness of interventions to prevent work-related eye injuries. Am J Prev Med 2000;18:27-33.

20 NIOSH National Occupational Research Agenda (NORA). Report on traumatic occupational injury research needs and priorities, US Department of Health and Human Services, Public Health Service, CDC, 1998.DHHS (NIOSH) publication no 98-134.

21 Weeks J, Levy B, Wagner G, eds. Preventing occupational disease and injury. Washington DC: American Public Health Association, 1991:245-9. 